\title{
Enterotoxigenic Clostridium perfringens and sporadic diarrhoea: a study from an Indian tertiary care hospital
}

Food-borne diseases present a growing health problem worldwide and over 200 different diseases are known to be transmitted by food (Bryan, 1982). Food safety has always been a very significant public health issue, but its global importance is not fully appreciated by many health authorities even now. In the United States, food-borne pathogens have been reported to cause 76 million cases and 5000 deaths each year (Mead et al., 1999). At present, the conventional means for diagnosing food-borne diarrhoea in the microbiology laboratory relies on the culture of bacteria from stool samples. Because there are many food-borne bacterial pathogens, such investigation is usually concentrated only on facultative bacteria. Analyses of food-borne anaerobic bacteria are not routinely performed due to difficulties in their isolation and identification. The role of Clostridium perfringens and its enterotoxin in food-borne diarrhoea is well known. More recently, C. perfringens enterotoxin has also been implicated as a cause of antibiotic-associated diarrhoea (Borriello et al., 1984), infectious diarrhoea (Larson \& Borriello, 1988) and sporadic diarrhoea (Luzzi et al., 1998; Brett et al., 1992). So far no information exists on disease prevalence from our country, even though it is well established in the west. This prompted us to carry out a prospective study to determine the role of enterotoxigenic $C$. perfringens in patients with sporadic, apparently non-food-related, diarrhoea in the Indian population using a duplex PCR and to type the isolates by multiplex PCR.

A total of 200 faecal specimens comprising 100 samples from single isolated cases of acute diarrhoea ( both from in-patients and out-patients) and 100 non-diarrhoeal controls received by the Anaerobic Laboratory of the All India Institute of Medical Sciences during the period January 2003-January 2005 were analysed for the presence of $C$. perfringens. All the specimens from which other enteropathogens (toxigenic Escherichia coli, Salmonella, Shigella, Vibrio, Staphylococcus aureus, Clostridium difficile) was isolated were excluded.

Tenfold diluted stool specimens were subcultured onto egg yolk agar (EYA) with neomycin and brain heart infusion agar (BHIA) with a $5 \mu \mathrm{g}$ metronidazole disc ( $\mathrm{Hi}$ media). Culture plates were incubated anaerobically at $37^{\circ} \mathrm{C}$ for $48 \mathrm{~h}$.

Identification of $C$. perfringens colonies was carried out by Gram stain, lecithinase production and other biochemical analyses as described previously (Joshy et al., 2006). Multiple colonies from each culture plate were stored at $-20^{\circ} \mathrm{C}$ in RCM broth with glycerol $(30 \%)$ for further analysis.

Detection of $C$. perfringens enterotoxin was performed on the stool specimen by reverse passive latex agglutination (RPLA) (PET RPLA kit; Denka-Sieken) and double sandwich-ELISA (R-Biopharm) using a commercial kit. The assays were performed according to the manufacturer's

instructions. The search for enterotoxin production by the isolate was performed after sporulating them in vitro in Duncan-Strong sporulation medium.

DNA was extracted from each culture-positive faecal specimen with the QIAamp rDNA stool mini kit (QIAGEN) and DNA extracts were stored at $-20^{\circ} \mathrm{C}$ before PCR. After thawing extracted DNA was added directly to the PCR assay as template. For PCR of C. perfringens stored isolates were cultured on $\mathrm{BHI}$ agar. One colony was suspended in $50 \mu \mathrm{l}$ sterile distilled water and heated to $100{ }^{\circ} \mathrm{C}$ for $10 \mathrm{~min}$. Supernatant $(10 \mu \mathrm{l})$ was used as template in the PCR. For enterotoxin gene detection PCR was done on stool samples as well as on the isolates by duplex PCR (Joshy et al., 2006). Toxinotyping of C. perfringens isolates were done using specific primers corresponding to the fragments of toxin genes as described previously (Joshy et al., 2006).
During the two year study period, a total of 200 faecal specimens were examined for $C$. perfringens. Stool specimens from 20 out of $100(20 \%)$ patients were positive for $C$. perfringens by culture. Of these $1 \%$ of samples were positive for $C$. perfringens enterotoxin by both RPLA and ELISA. Duplex PCR analysis for enterotoxin gene detection, also showed that $1 \%$ of samples were positive for enterotoxin gene.

Of 100 non-diarrhoeal controls 27 (27\%) C. perfringens strains were isolated. None of the samples were positive for enterotoxin either by RPLA, ELISA or by PCR.

Multiplex PCR indicated that all the isolates were of type A, containing only the $\alpha$ toxin gene, $\beta, \varepsilon$ and $\iota$ genes were absent.

In this study we tried to find an answer to the question whether or not enterotoxin-producing C. perfringens strains are casually related to sporadic diarrhoea in our population. Samples known to contain other pathogens were excluded because it would be difficult to interpret the significance of the presence of C. perfringens enterotoxin in addition to other enteropathogens such as Salmonella. The RPLA kit has been used to investigate cases of sporadic diarrhoea; positivity rates for enterotoxin in faecal specimens ranged from 2.5 to $18 \%$ (Samuel et al., 1991; Brett et al., 1992; Mpamugo et al., 1995;

Tompkins et al., 1999; Forward et al., 2003). However, there have been problems with the specificity of this test (Food Standards Agency, 2000) and none of those studies involved enterotoxin analysis at the molecular level.

In our study 1 of the 47 isolates gave positive results for both $p l c$ and cpe genes (the presence of 2 bands of phospholipase $\mathrm{C}$ gene (283 bp) and enterotoxin gene (426 bp) by duplex PCR. This suggested a prevalence of $2 \%$ of $C$. perfringens carrying the cpe gene. The observed prevalence of cpe gene in $C$. perfringens strains isolated from faecal specimens in this study was close to 
those recently reported in molecular epidemiology surveys. Those surveys suggested that only a low percentage $(<5 \%)$ of all C. perfringens isolates from various origins carried the cpe gene (Kokai-Kun et al., 1994; Van

Damme-Jongsten et al., 1989) whereas the percentage is higher among $C$. perfringens strains isolated from confirmed outbreaks of food poisoning.

None of the C. perfringens isolated from healthy controls were carrying the cpe gene or were positive for enterotoxin, ruling out the possibility of a carrier state in the analysed group. Toxinotyping showed that all our isolates belonged to type A, which is similar to the other studies reported. Since the numbers of strains analysed is less in the current study, a greater number of strains should be studied before reaching to a conclusion regarding the prevalent geographical types in the area.

Many investigators have described a relation between enterotoxin production and sporulation of $C$. perfringens (Carman, 1997; Duncan, 1973; Zhao \& Malville, 1998). Of the isolates $81 \%(38 / 47)$ were producing spores; however, only $2 \%$ were producing enterotoxin in vitro.

The tests that have been used by previous investigators for diagnosis of $C$.

perfringens-associated diarrhoea involved the direct detection of faecal enterotoxin, quantitative stool cultures for $C$. perfringens and the absence of other enteric pathogens in stool specimens. In the present study, we were not able to determine the association between cpe gene positive $C$. perfringens in the patient group and other factors, due to the low prevalence of cpe gene detected in $C$. perfringens strains isolated from these patients. From this study the cpe gene positive case was detected in a patient $>15$ years, who had fever and abdominal pain. Diarrhoea was of a duration $>3$ days. Diarrhoea lasting longer than 2 days has been reported in other studies of non-food-borne human gastrointestinal diseases, including antibiotic-associated diarrhoea and sporadic diarrhoea cases (Borriello et al., 1984; Mpamugo et al., 1995). It was also reported that infection was common in the elderly, and symptoms are more severe and longer in duration than those of $C$. perfringens type A food poisoning (Mpamugo et al., 1995).

To conclude, the results presented here support the fact that sporadic diarrhoea can be caused by enterotoxigenic $C$. perfringens. However, considering the low frequency of enterotoxin in faecal specimens in this study, C. perfringens seems to have a limited role in the analysed sporadic diarrhoeal population. The application of these molecular techniques to detect $C$. perfringens, as well as its enterotoxins and their typing, will help not only in diagnosis, but also in epidemiology of infection in various $C$. perfringens outbreaks. This duplex and multiplex PCR will also help us to implicate the aetiology or associating role of $C$. perfringens in diverse clinical syndromes. In the current situation of increasing numbers of immunocompromised patients this relatively mild organism might lead to serious/fatal diseases, if left unrecognized.

\section{Acknowledgements}

This work was supported by Indian Council of Medical Research, New Delhi, India.

\section{Lovely Joshy, ${ }^{1}$ Rama Chaudhry, ${ }^{1}$ Benu Dhawan, ${ }^{1}$ B. K. Das, ${ }^{1}$ Lalit Kumar $^{2}$ and Shobha Broor ${ }^{1}$ \\ ${ }^{1}$ Department of Microbiology and ${ }^{2}$ Dr B. R. Ambedkar Institute-Rotary Cancer Hospital, All India Institute of Medical Sciences, New Delhi, India \\ Correspondence: Rama Chaudhry (drramach@rediffmail.com or ramach003@yahoo.com)}

Borriello, S. P., Larson, H. E., Welch, A. R., Barclay, F., Stringer, M. F. \& Bartholomew, B. A. (1984). Enterotoxigenic Clostridium perfringens: a possible cause of antibiotic-associated diarrhoea. Lancet 1, 305-307.

Brett, M. M., Rodhouse, J. C., Donovan, T. J., Tebbut, G. M. \& Hutchinson, D. N. (1992). Detection of Clostridium perfringens and its enterotoxin in cases of sporadic diarrhoea. J Clin Pathol 45, 609-611.

Bryan, F. L. (1982). Diseases Transmitted by Foods. Atlanta, GA: Centers for Disease Control.

Carman, R. J. (1997). Clostridium perfringens in spontaneous and antibiotic-associated diarrhoea of man and other animals. Rev Med Microbiol 8, S43-S45.
Duncan, C. L. (1973). Time of enterotoxin formation and release during sporulation of Clostridium perfringens type A. J Bacteriol 113, 932-936.

Food Standards Agency (2000). A Report of the Study of Infectious Intestinal Disease in England. London: The Stationery Office.

Forward, L. J., Tompkins, D. S. \& Brett, M. M. (2003). Detection of Clostridium difficile cytotoxin and Clostridium perfringens enterotoxin in cases of diarrhoea in the community. J Med Microbiol 52, 753-757.

Joshy, L., Chaudhry, R., Dhawan, B., Kumar, L. \& Das, B. K. (2006). Incidence and characterization of Clostridium perfringens isolated from antibiotic-associated diarrhoeal patients: a prospective study in an Indian hospital. J Hosp Infect 63, 323-329.

Kokai-Kun, J. F., Songer, J. G., Czeczulin, J. R., Chen, F. \& McClane, B. A. (1994). Comparison of Western immunoblots and gene detection assays for identification of potentially enterotoxigenic isolates of Clostridium perfringens. J Clin Microbiol 32, 2533-2539.

Larson, H. E. \& Borriello, S. P. (1988).

Infectious diarrhoea due to Clostridium perfringens. J Infect Dis 157, 390-391.

Luzzi, I., Caprioli, A., Bissichia, R.,

Ciammarugh, R. \& Mastrantonio, P. (1998). A sporadic case of diarrhea due to enterotoxigenic C. perfringens. Microbial Ecol Health Dis 1, 69-70.

Mead, P. S., Slutsker, L., Dietz, V., McCaig, L. F., Bresee, J. S., Shapiro C., Griffen, P. M. \& Tauxe, R. V. (1999). Food-related illness and death in the United States. Emerg Infect Dis 5, 607-625.

Mpamugo, O., Donovan, T. \& Brett, M. M. (1995). Enterotoxigenic Clostridium perfringens as a cause of sporadic cases of diarrhoea. J Med Microbiol 43, 442-445.

Samuel, S. C., Hancock, P. \& Leigh, D. A. (1991). An investigation into Clostridium perfringens enterotoxin associated diarrhoea. J Hosp Infect 18, 219-230.

Tompkins, D. S., Hudson, M. J., Smith, H. R. \& 8 other authors (1999). A study of infectious intestinal disease in England: microbiological findings in cases and controls. Commun Dis Public Health 2, 108-113.

Van Damme-Jongsten, M., Wernars, K. \& Notermans, S. (1989). Cloning and sequencing of the Clostridium perfringens enterotoxin gene. Antonie Van Leeuwenhoek 56, 181-190.

Zhao, Y. \& Malville, S. B. (1998). Identification and characterization of sporulation-dependent promoters upstream of the enterotoxin gene (cpe) of Clostridium perfringens. J Bacteriol 180, 136-142. 